\title{
A Call to Action: Introducing the Initiative for Eradicating Racism
}

\author{
Danielle T. Ligocki \\ Oakland University
}

\author{
Robert A. Martin \\ Oakland University
}

\author{
Chaunda L. Scott \\ Oakland University
}

In June of 2020, several faculty and staff members in the School of Education and Human Services at Oakland University in Rochester, Michigan began developing plans to launch a new project entitled The Initiative for Eradicating Racism. This article begins by defining key terms used throughout the article, followed by underscoring the purpose and need for this type of academic initiative. Next, the frameworks used to guide the development of this initiative are highlighted, along with a brief introduction of the current diversity, inclusion, and social justice efforts in progress in the School of Education and Human Services. Lastly, we share our plans to move from our current initiative status to a self-sustaining center in the near future.

Keywords: racism, eradicating racism, social justice, educational equity

\section{INTRODUCTION}

We begin this article by introducing three key terms used throughout this discussion. The first key term defined is racism. We define racism as a long-standing, socially accepted structure that oppresses people of color for the purpose of advantaging a non-racially identified group socially, economically, educationally and politically. The second key term defined is eradicating racism. Eradicating racism is defined as dismantling all forms of racism (i.e., individual, institutional, systemic, and cultural racism) that persistently oppress and often deny people of color their civil rights and access to equal opportunities in education, healthcare, housing, and employment. The third key term is social justice. Social justice is defined as a necessary, socially accepted practice in which all citizens' civil rights are upheld, all citizens are treated with dignity and respect, and all citizens have fair access to public services and educational, healthcare, housing, and employment opportunities.

When defining racism, it is important to push back on the commonly held belief that racism manifests only as conscious racism or individual racism, which are the types of racism where one actively holds negative and harmful ideas, beliefs, and assumptions about people based on the race they appear to be. This type of racism often reveals itself in hate speech or discriminatory action and is the easiest to identify, but also the easiest to deny. Many people believe that if they are not vocal about their racist thoughts and 
actions, then they are not racist. This leads into the next type of racism, often called "unconscious racism". Lincoln Quillian (2008) describes unconscious racism as racism based on societal imagery and messages that shape our view of the world. While one may not actively hold or act on racist ideology, their actions, even subtle, are based on racist ideology that has been internalized. Unconscious racism is often at the heart of systemic racism and institutional racism, where one can see policies, rules, and laws that create and uphold inequalities along racial lines. This type of racism is foundational in American society and Ijeoma Oluo, author of So You Want to Talk about Race, explained this concept clearly during an interview with Noel King on NPR in 2020. Oluo stated,

The framing around racism has always been there is a white person who doesn't like people of color or a Klan member or someone, you know, who's making their hatred and ignorance very obvious. But what's actually been impacting our lives are systems that rely on subtle and not so subtle biases against people of color to disempower us and put us at risk. And so we've been fighting for job opportunities, for safety from violence, for equal education, for freedom from medical racism. And that is upheld not by how you love or don't love people of color but by how you participate with our systems. (2020)

While all types of racism manifest themselves in different ways, it is important to acknowledge that each type of racism is harmful to people of color, specifically Black people. When thinking about the role one might play in regard to racism, it is important to think about individual behavior, but this is difficult when considering what Joyce King defines as dysconscious racism. King explains dysconsciousness as "an uncritical habit of mind (including perceptions, attitudes, assumptions, and beliefs) that justifies inequities and exploitation by accepting the existing order of things as given" (1991, p.135). This is especially problematic when applied to racism, as dysconscious racism is a form of racism that "tacitly accepts dominant White norms and privileges" (p. 135). This means that rather than possessing a critical consciousness regarding the state of race relations in the world, many people choose to go about their business, blindly accepting the status quo, neglecting to question their own place as it relates to race and privilege, and leaving social inequities unexplored and unexamined. This is one type of thinking and behavior that the Initiative for Eradicating Racism is looking to dismantle, as it can be far more insidious than the explicit, outward facing acts of racism that many think about when they think about racism and thus, excuse themselves from it.

\section{PURPOSE}

In providing a historical context for this initiative, it is important to look back on the work that has been done across the School of Education and Human Services in the years leading up to this initiative. In 2016, a small committee called the Multicultural Education Committee was one of the few entities in the building that sought to address any kind of societal issues through different types of educational and informal programming. However, at that time, the committee had consisted of four people, and they often held just one event per year. After serving for two years on the committee, Dr. Ligocki decided it was time to make some changes. She took over as chair of the committee, sent out an all-school invitation to recruit new members, and eventually secured recognition as a legitimate committee with an annual budget. With these steps complete, the committee grew from just four members in 2017 to more than a dozen members today. The committee also elected to change its name, moving away from the antiquated term 'multicultural education' and instead delineating what the committee stands for, believes in, and is working toward. Thus, the committee was renamed the Committee for Diversity, Equity, and Inclusion. At the start of the 2020 academic year, this committee now boasts 18 members, which include both faculty and staff and who represent all but one of the departments across the school.

This committee has accomplished a great deal of work over the past few years. For example, the committee drafted a position statement on social justice, shared it with faculty and staff, and later revised this position statement in order to reflect the feedback that faculty and staff provided. Additionally, the 
committee wrote a new mission statement and held a number of events that faculty, staff, students, and community members all attended. One such event was an evening with Dr. Crystal Laura to engage in a conversation about the School to Prison Pipeline. The Committee for Diversity, Equity, and Inclusion also held an invited speaker session that asked a diverse group of panelists to respond to the question: "Does race still matter in America?" Additionally, the committee has held events that focused on the election in 2016, on students with special needs, and on sexism in society. While this committee works to address diversity, equity, and inclusion more broadly, a deep commitment to eradicating racism supports this work, and many members of the Diversity, Equity, and Inclusion Committee are involved in the Initiative for Eradicating Racism. The work of this committee provided fertile ground over the years for the development of the partnerships that began the work of the current initiative.

In addition to these larger events, the Diversity, Equity, and Inclusion Committee also began a monthly book study that invited faculty and staff from across the school to engage in critical readings and discussions. Using the text Readings for Diversity and Social Justice by editors Adams, Blumenfeld, Castaneda, Hackman, Peters, and Zuniga (2018), the committee chose readings each month that would encourage personal reflection with the goal of movement toward action within the school. While these book studies did not always garner high attendance, they served as the springboard for continued work in this area, and an ongoing focus on embedding equity and anti-racist work throughout all teaching, scholarship, and service within the School of Education and Human Services. These book studies led the way to events focused on conversation and action. During the summer of 2020, this group had a Town Hall in order to discuss the state of race in society, and provide resources to faculty and staff that might help lead to action. Additionally, the committee started collaborating with student groups across campus to hold 'Compelling Conversations', which work to center voices such as the Black Graduate Students group, as well as local authors and people of color. These conversations have been well attended by faculty, staff, and students and the hope of the committee is to continue these partnerships.

As this committee continued to grow and expand their work, other partnerships were blooming as well. In the Winter of 2019, Dr. Ligocki and Dr. Martin, faculty members in the School of Education and Human Services, sat down to talk about their shared experiences in education, and the glaring need for more men of color in the teaching profession. As of 2017, only $2 \%$ of the teaching force was composed of Black men, a statistic that has very real consequences for all students, but especially students of color (Hanford, 2017). This conversation lit a spark and conversations started throughout the School of Education and Human Services to begin an initiative that would help to recruit and retain more faculty of color, especially men. This initiative also includes recruitment and retention of students of color, and those from traditionally marginalized groups. At this same time, Dr. Scott, also a faculty member in the School of Education and Human Services whose research focuses on workforce diversity, current and emerging trends, and eradicating societal racism had been thinking about how Oakland University could raise awareness of the critical need to eradicate societal racism and thus brainstormed the idea for a Center for Eradicating Racism. When Drs. Ligocki and Martin heard what Dr. Scott was beginning to propose, it seemed like the perfect time to start collaborating, and that is when all three faculty members began imagining what this center might look like, the role it might play, and the kind of support that would be needed.

Over the next few months, as the Covid-19 Pandemic shut down all in-person interactions and meetings, the collaboration continued electronically. However, the critical need for this work to continue moving forward came immediately after the murder of George Floyd in Minneapolis, Minnesota. While all three faculty members involved in this type of work always knew that racism ran deep in society and institutions of education, it became clearer than ever that there was an imperative need to move from awareness and polite conversation to conversations that result in action. It was during this time that a few other faculty and staff members joined the efforts and work began to define the mission and vision, what types of work the center planned to engage in, and how to get more faculty and staff members across the school involved. After a meeting with administrators, the authors realized that - at least for the first year - the proposed center would need to start as the Initiative for Eradicating Racism, with the hopes of moving towards a center within a year or two. It was during these discussions that the group created a shared a vision for this initiative, which reads: 
We as members of the Oakland University School of Education and Human Services recognize the role we have to play in dismantling racism. We have the responsibility to educate our colleagues, students, and our community partners and to influence policy to further the cause of dismantling racism in the United States. To that end, we seek to provide a center for eradicating racism and beginning racial healing in our community.

From this vision, the group was able to define what this work looks like across the areas of research, teaching, practice, and service, as a means to keep the initiative embedded throughout all facets of the School of Education and Human Services, rather than as a one-time training. As referenced in a recent article in the Chronicle of Higher Education (Brown, 2020) a reliance on one-time-only diversity training does little to leave a lasting impression on those who take part. Instead, anti-racist work needs to be ongoing and embedded in the culture of an institution, and constantly followed up on with dialogue and discussion. That is one of the main goals as the work to establish the Initiative for Eradicating Racism continues.

\section{CO-AUTHORS' POSITIONALITY STATEMENTS}

When working on a large-scale initiative that is personal in nature, but with far-reaching consequences, it is important to be transparent about identity, and the personal and professional experiences that have shaped the perspectives of the professionals involved in that work. With this in mind, the faculty members involved in this initiative share their positionality statements below.

\section{Dr. Danielle T. Ligocki}

Dr. Ligocki is currently in her fifth year at Oakland University in the department of Teacher Development and Educational Studies, after having spent eleven years teaching junior high school before entering higher education. She spent her first three years teaching in two different, predominantly white, middle class school districts. These first three years left her immensely unhappy with teaching, though she was not sure why. However, when she took a job in a school district with greater diversity in race and class, she found her niche and realized how much she had to learn about herself, her own identity and biases, and how to work with students and families who did not look like she did.

It was over the course of these last eight years of her career that she realized the deep inequities in schools and education, especially as they pertained to students of color and the schools and teachers who served them. In 2011, Dr. Ligocki entered a doctoral program focused on social justice and equity in society and education and this is when her passion for, and deep understanding of, anti-racist education began. Over the course of four years in this program, she realized that her personal and professional commitments resided deeply in making change not only in education, but in society, and this has been the focus of her work ever since. As a white, cisgender, straight female, Dr. Ligocki realizes that she has certain privileges as they pertain to her place in education. However, as a first generation college student from a working class background, she also has a different lens through which to view inequities in education.

\section{Dr. Robert A. Martin}

Dr. Martin, a special instructor in the Department of Organizational Leadership, is currently in his fourth year at Oakland University, after having spent 38 years in K-12 education. One year, while visiting Rio de Janeiro, Brazil, a woman genuinely inquired, "How does it feel to overcome predetermined obstacles in your life?" Dr. Martin met her question with a confused stare. Upon reflection, he assumed she was referring to what she saw: a Black male, raised by a divorced single-mom in inner city Detroit. It is a fact that Dr. Martin faced multiple environmental factors that might predict stereotypical outcomes. However, his mother, who was an educator, never succumbed to a victim mentality and refused to tolerate that mindset in him.

Surrounded by extended family and a close-knit community, Dr. Martin rarely felt isolated or unsupported. He grew up in a predominantly Black neighborhood, school, and church. His white teachers were the only non-Black people he had significant interaction with on a regular basis. Always the classic 
'teacher's pet' in school, Dr. Martin loved to read, earned good grades, had minimal discipline issues, and spent much of his time emotionally hidden. However, his life blossomed into Technicolor when he arrived at Detroit's Cass Technical High School. Educators there viewed Dr. Martin's quirky interests and personality as an asset, rather than as a deficit.

The intersectionality of race and excellence continued to motivate most of Dr. Martin's career decisions. From serving as the first Black teacher and administrator at Luckett Christian Academy and the only Black teacher at Southfield-Lathrup High School for a few years, to advocating for Culturally Responsive environments as a principal and eradicating achievement disparities as a consultant, central administrator, and university faculty member, Dr. Martin's work has always been undergirded by the fight against systemic racism.

\section{Dr. Chaunda L. Scott}

Dr. Scott is an African American woman from Minneapolis, Minnesota who is an Associate Professor of Human Resource Development in the Department of Organizational Leadership housed in the School of Education and Human Services at Oakland University. For the past 20 years, she has focused her teaching, research, and service activities on the areas of adult diversity and social justice education, workforce diversity, current and emerging trends, and eradicating societal racism. One of Dr. Scott's primary goals in academia is to be an example of how to use your platform and voice in the areas teaching, scholarship, and professional service endeavors to raise awareness of and challenge all forms of racism and economic inequalities imposed on individuals who lack power, privilege and resources. Dr. Scott's purpose for being committed to these areas are twofold: 1) To further the work of Dr. Martin Luther King, Jr. by advocating for the eradication of societal racism and promoting equality for all people, which lies at the heart of the human dream and, 2) To help her students, colleagues, friends, and community members understand their roles in helping to create an equitable and racism-free society for all citizens to live and prosper in.

\section{SUPPORTING THEORETICAL FRAMEWORKS}

One foundational theory closely aligned with the Initiative for Eradicating Racism is Critical Race Theory (CRT) (Delgado \& Stefanic, 1993). Ladson-Billings \& Tate (1995) introduced CRT by identifying race as a significant factor in education and they brought to the discussion the intersectionality of race and whiteness as property. They advocated for a critique of intent versus outcomes and the value derived from multiple perspectives. Racial achievement disparities, educational policies that support the culturally dominant narrative, and white hegemony in education influence policies and practices in PK-16 education in the United States and these policies and practices uphold and maintain systemic racism. Current racism is anchored not only in white hegemony and in whiteness as a thing beyond personhood, but in skin color and the value derived from skin color as property (Harris, 1993).

An expansive view of whiteness as a process, position, or social location is also key to understanding this work (Charbeneau, 2015). Whiteness as a process is a stance that allows most white people to interact in society with intentional obliviousness and a denial of racism (Leonardo, 2004). This preference is combined with the tension of living in the illusion of a colorblind and post-racial society, while rejecting the need to acknowledge difference of race or debate the dismantling of institutional racism. This sets up parallel dimensions where non-whites are forced to learn the grammar of whiteness (Bonnilla-Silva, 2012) while navigating white culture, even though it does not matter what behaviors or skills they develop -people of color in a world dominated by whiteness will always be seen through a deficit lens.

Solorzano \& Yosso (2002) offer an expanded definition of CRT in education when they spell out the following key steps: 1 . Recognizing the subordination of race; 2 . Acknowledging the dominance of white culture; 3. Critiquing the double-edged nature of social justice initiatives; 4. Valuing experiential learning as equal to empirical knowledge (i.e., the counter-story), and 5. Inviting and embracing interdisciplinary perspectives and research. These steps give a glimpse into the type of work that the Initiative for Eradicating Racism is devoted to and the next section will connect this theoretical definition to a framework with guidelines for IER's work and beyond. 
The symbolic nature of whiteness mentioned above is embedded in structures and institutions everywhere. The twin myths of United States exceptionalism and meritocracy in higher education serve as barriers to challenging practices and policies resulting in disparate outcomes. Most citizens of the United States would vehemently reject overtly racist behavior or ideology. However, in the 21 st century, it is the hidden rules of othering that are difficult to challenge and explicitly dissect. The process of whiteness that is embedded in economic policies and status symbols remain as powerful reminders to non-whites (Christian, 2019) that racism is far from a thing of the past. These fears, anxieties, and assumptions create and maintain mental and emotional separation. They also serve as inhibitors of motivation and progress, thereby reinforcing and strengthening the whiteness process. Derek Bell (1995) reminds us that there are sociocultural forces at work that are constantly shaping perceptions, experiences, and responses to racism, and that is exactly why Critical Race Theory must be understood on a deep level.

A final foundational framework that aligns with the Initiative to Eradicate Racism is the Critical Racism Pedagogy Model. The Critical Racism Pedagogy Model, developed by Drs. Marilyn Byrd and Chaunda L. Scott, (2010) builds off the fundamental themes of Critical Theory, Critical Pedagogy, Critical Race Theory, and the lived experiences of being professional African-American women who have been confronted by racism in America. Byrd and Scott's (2010) four step Critical Racism Pedagogy Model is a structured facilitation tool that can be used to support and guide educators and organizational leaders in: 1) leading constructive dialogue on all forms of racism (i.e., individual racism, institutional racism, cultural racism and systemic racism); 2) providing examples of how historical forms of racism persist in our contemporary society and promote hate, discrimination, stereotyping, inequality, injustice, and division and; 3) engaging in dialogue that is focused on developing and sharing ideas and doable strategies that can aid in eradicating all forms of societal racism .

To utilize the Critical Racism Pedagogy facilitation framework, educators and practitioners should follow the four steps below:

- Step One - Educate: Introduce an historical aspect of racism by viewing various forms of media (video clips, documentaries, and related films) or assign reading that illustrates and emphasizes racism as a critical social ill.

- Step Two - Educate: Identify and discuss modern day recurring patterns of historical racism as highlighted in contemporary forms of media and readings (films, documentaries, TV shows, and newspaper articles)

- Step Three - Educate: Identify and develop doable strategies for dismantling all forms of racism using structured dialogue

- Step Four - Social Justice: Take action by implementing the doable social action strategies that have been identified and developed.

The Outcome - Diversity Education Strategies that Result in Social Action: The Critical Racism Pedagogy Model by Byrd and Author (2010) is a practical facilitation tool that educators and practitioners can draw upon to guide critical discussions on all forms of racism in the classroom, the boardroom, and now by the Initiative for Eradicating Racism at Y University. The utility of the Critical Racism Pedagogy framework lies in its ability to use structured dialogue to uncover socially accepted historical and contemporary racial beliefs and practices that have allowed various forms of societal racism to persist. Additionally, the Critical Racism Pedagogy framework has a clear commitment to education and taking action, which makes social action its goal. This clear movement from inward reflection to outward action aligns well with the Initiative for Eradicating Racism at Y University.

\section{INITIATIVE FOR ERADICATING RACISM}

The May 25, 2020 murder of George Floyd startled the nation to a level of alertness not experienced in the United States for decades. One week after Mr. Floyd's murder, on June 1, 2020, Dr. Jon MargerumLeys, dean of Oakland University's School of Education and Human Services, sent a letter to the SEHS faculty and staff outlining his dismay at racially motivated, senseless acts of violence. "As a school, we are 
called to do the best of what we have always done. To support, to advocate, to educate, to heal, to lead." By this time, Dean Margerum-Leys had held discussions with Drs. Ligocki, Martin, and Scott discussing the emerging concept of an Initiative for Eradicating Racism. With this in mind, he ended his letter to SEHS faculty and staff with an invitation for individuals "interested in participating in this effort, [to] please let him know." From this invitation, 17 faculty and staff members responded and the work to support the Initiative for Eradicating Racism continued.

Through the IER, faculty and staff examine the ways in which historical and contemporary forms of institutional racism have perpetuated racial inequalities in communities of color. This structural racist legacy began when schooling in the United States started for the sons of white male landowners, continued through Jim Crow segregation, and was exacerbated by the Brown vs. Board 1954 Supreme Court decision. This level of societal racism continues to exist today as prolific educational disparities in the 21 st century persist. Furthermore, faculty and staff involved in the IER propose specific action strategies derived through education, leadership, teaching, research, practice, and service activities. The aim is for individuals across campus and beyond to begin the practice of eradicating racial inequalities in society and promoting racial healing.

Like other institutions in the United States, the educational system as a whole must confront its role in upholding white supremacy. Disparities between disciplinary measures taken against Black and Brown students and their white peers are evident as early as preschool. These inequities compound throughout the PK-16 system and are deeply intertwined with the special education system and the ways in which behavior is addressed in schools. This leads to an over suspension and expulsion of Black and Brown students, high dropout rates, the pushing out of students of color, and ultimately contributes to the School-to-Prison pipeline (Laura, 2014). Eradicating racism means society and its institutions of education cannot ignore the way white supremacy is upheld, modeled, and transmitted to students in educational settings. There must be a re-examining of everything, from the way future leaders, educators, counselors, and other Human Resource professionals are trained to address implicit bias, systemic racism, and the world around them, to the textbooks used in classes, and the officials tasked with making policy decisions.

With this in mind, the IER's 2020-2021 goals and objectives are as follows:

I. Hosting a 2021 Lecture Series and Symposium entitled "Dismantling Racism"

II. Assembling an IER Advisory Council with area business and community leaders

III. Collecting and analyzing SEHS diversity, recruitment, and retention data

IV. Co-sponsoring the Annual 2021 Oakland University Diverse Voices Conference (a higher education student conference). The theme of this virtual conference is: "Defining the Role of Social Justice in Practice"

Leadership within the School of Education and Human Services and throughout Oakland University must be committed to the work of eradicating racism. That means a willingness to dismantle all systems that uphold, promote, transmit, or abide white supremacy. This commitment is not a statement of solidarity, but rather a call to action for the School of Education and Human Services, as well as all OU stakeholders to make equity and belonging a central focus in our campus community.

It is important to note, however, that this university is not starting at zero. There has been ongoing work throughout the School of Education and Human Services that speaks to a commitment to social justice and equity in education. For example, four years ago, the elementary education program began a large-scale redesign in order to better meet the needs of future students and educators, as well as to address the changing state standards. As the work of the redesign was undergoing its beginning phases, Dr. Ligocki made clear that there must be an explicit commitment to preparing pre-service teachers to be transformative educators, which includes a clear relationship with educating for social justice and equity. While this was met with resistance by those who felt this would "indoctrinate" students, this element of the redesigned program was viewed as a non-negotiable and thus undergirded four years' worth of redesign work. As the program prepares to roll out in Fall 2021, there are elements of social justice and equity found in all courses in the professional sequence, as well as one course devoted entirely to diversity, equity, and inclusion, both in education as well as in society. 
In addition to the redesigned program at the undergraduate level, Dr. Scott has provided Oakland University students at the undergraduate and graduate level with an opportunity to speak out publicly on the topics of eradicating societal racism and valuing all aspects of human diversity at the annual Diverse Voices Conference (DVC), which she founded in 1998 (Scott, 2016). The goal of the DVC is to: 1) provide students a town hall forum teaching and learning atmosphere on campus to lead and hear real world lectures on critical race theory, human diversity, and inclusion topics in front of their parents, peers, faculty members, administrators, and community members, and 2) prepare students to be world social justice leaders now and in the future who speak out against all forms of human injustices. The success of the DVC to date is student-driven as measured by the increasing numbers of students who represent a variety of diverse backgrounds that volunteer to present each year.

In 2019, Dr. Scott also launched The Oakland University Graduate Certificate in Human Diversity, Inclusion, and Social Justice (Oakland University Graduate Human Diversity Inclusion and Social Justice Certificate Program, n.d.). This certificate program is designed for graduate students and professionals who are interested in advancing their understanding of human diversity, inclusion, and social justice issues in the workplace and society from a historical and contemporary perspective. It is also set up in a way that supports students in acquiring specialized knowledge, skills, abilities, and strategies to advocate for, lead, and assist with the development and implementation of human diversity, inclusion, and social justice efforts in a variety of professions globally. This certificate program also meets the increasing local and national need to equip current private and public sector professionals with critical competencies to work effectively in an increasingly diverse workforce and country. Lastly, this critical and timely certificate program provides a unique opportunity for graduate students and professionals to acquire the skills necessary to support and sustain the increasing number of career positions that are emerging in the areas of human diversity, inclusion, and social justice.

\section{CONCLUSION}

The name of this initiative alone sets up a daunting task: "eradicating racism". However, the reality is that there is no other way. The Initiative for Eradicating Racism is a group that is no longer interested in polite conversation. Instead, it is a group looking for action in order to make real, lasting change in the school, across the campus, and in the surrounding community. While this is not work that will be done quickly or easily, it is work that must be done. In order to begin the process of moving from an initiative towards a self-sustaining center that will work with students, faculty, staff, and the surrounding community, an action plan is in place.

First, the group that leads the Initiative for Eradicating Racism is collaborating with Fisk University, an HBCU (Historically Black College and University), to plan a four-part lecture series that will culminate in a symposium. This series will draw from scholars across all disciplines, including those in Art, Music, Literature, Education, Human Resources, Leadership, and Policy in order to present a multi-disciplinary approach to anti-racist pedagogy, content, and topics. Additionally, the IER is working to build a relationship with those in the business community in order to generate both partnerships and funding as a way to build a sustainable center to continue this work. Finally, the IER anticipates working across the areas of scholarship, teaching, practice, and service to ensure that anti-racist work is visible across all facets. This will not happen quickly, but this group is committed to focused, detailed action in order to continue to work towards eradicating racism at the school level, the university level, and in the community and beyond.

When looking at the area of research, the plan is to develop a journal situated at Oakland University and within the future center, which invites work on eradicating racism and the types of scholarship that faculty and students are doing in this area. Additionally, this group intends on providing more support for graduate students who study and write about all types of racism; developing a scalable assessment tool that can help assess racial attitudes; and advocating for greater support for individual faculty members who have research agendas that focus on race, education, and teaching. Currently, several scholars in the Department of Teacher Development and Educational Studies, the Department of Organizational Leadership, and the Department of Reading and Language Arts are all involved in research and scholarship that works to elevate 
diverse voices, draw attention to inequities in education, and highlight the need for anti-racist work with pre-service teachers. Our hope is to elevate and support this ongoing work, while supporting the development and enactment of new research projects as well. As a group, it is imperative that the research that comes out of this initiative and future center is deeply committed to action that works to eradicate racism.

Finally, in the area of service, the IER has plans that include conducting professional development workshops, both within SEHS as well as in the surrounding community, while continuing with regularly scheduled book study meetings and critical conversations that have been occurring for two years. In addition to these main practices, the IER intends on offering community service projects that focus on racial healing, while offering intensive training for university leaders and community leaders in order to prepare them with the tools and knowledge they need to assist in dismantling racism in their institutions. Part of this service work also includes an insistence on not just recruitment of professors and students who are from traditionally marginalized groups, but also working actively to retain them. It is immoral to recruit people of color if institutions are still functioning in a state of systemic racism. Finally, the IER hopes to create a webpage that includes resources, tools, and information that will aid in eradicating all forms of racism.

The best way to go about this work is to have support beyond the campus of Oakland University. Therefore, Drs. Ligocki, Martin, and Scott are currently collaborating with the Oakland University Office of Corporate and Foundation Relations to put together an IER Advisory Council composed of leaders in the surrounding area, with the support of faculty and staff within the School of Education and Human Services, as well as other professionals across Oakland University. By engaging leaders in business and community, not only will the Initiative for Eradicating Racism have the support of more voices, but it will also be able to secure funding that will help meet the goal of moving this initiative to a self-sustaining center. While this group realizes dismantling oppressive systems and eradicating racism is not easy work, there is a strong conviction that it is imperative, now more than ever, if there is any hope of moving this country forward in a way that demands social justice for all. The time is now.

In this article, we have highlighted the work that the IER is committed to achieving. In doing so, we want to encourage academic institutions and places of business globally to consider developing efforts in teaching, scholarship, and service that promote the eradication of societal racism. It is our hope that this article will be viewed as a call to action, because as academics, we all have a role to play in eradicating societal racism, in its many forms.

\section{REFERENCES}

Bell, D. (1995). Who's afraid of critical race theory? University of Illinois Law Review, 4, 893-910.

Bonilla-Silva, E. (2011). The invisible weight of whiteness: The racial grammar of everyday life in contemporary America. Ethnic and Racial Studies, 35, 173-194.

Brown, S. (2020 September 27). The Trump Administration Says Diversity Training Can Be Harmful. What Does the Research Say? Chronicle of Higher Education. Retrieved from https://www.chronicle.com/article/the-trump-administration-says-diversity-training-can-beharmful-what-does-the-research-say?cid=gen_sign_in

Byrd, M.Y., \& Scott, C.L. (2010). A framework integrating dialogue on forms of racism within Human Resource Development workforce diversity courses and workforce diversity settings: Implications for HRD. In Proceedings of the 2010 Academy of Human Resource Development Conference (pp. 1315-1336). Knoxville University of Tennessee, Knoxville.

Charbeneau, J. (2015). White faculty transforming whiteness in the classroom through pedagogical practice. Race Ethnicity and Education, 18(5), 655-674.

Christian, M. (2019). A global critical race and racism framework: Racial entanglement and deep and malleable whiteness. Sociology of Race and Ethnicity, 5(2), 169-185.

Delgado, R., \& Stefanic, J. (1993). Critical race theory: An annotated bibliography. Virginia Law Review, $79,461-516$. 
Hanford, E. (2017). Why are there so few Black male teachers? Retrieved from https://www.apmreports.org/story/2017/08/28/why-so-few-black-male-teachers

Harris, C. (1993). Whiteness as property. Harvard Law Review, 106(8), 1707-1791.

King, J. (1991). Dysconscious racism: Ideology, identity, and the miseducation of teachers. Journal of Negro Education, 60(2), 133-146.

King, N. (Host). (2020, July 1). What systemic racism means and the way it harm communities [Audio podcast episode]. In Morning Edition. NPR. Retrieved from https:/www.npr.org/2020/07/01/885878564/what-systemic-racism-means-and-the-way-it-harmscommunities

Ladson-Billings, G., \& Tate, W.E. (1995). Towards a critical race theory of education. Teachers College Record, 97(1), 47-68.

Laura, C. (2014). Being bad: My baby brother and the school-to-prison pipeline. New York City, NY.: Teachers College Press.

Leonardo, Z. (2004). The color of supremacy: Beyond the discourse of 'white privilege'. Educational Philosophy and Theory, 36(2), 137-152.

Quillian, L. (2008). Does unconscious racism exist? Social Psychology Quarterly, 71(1), 6-11.

Scott, C.L. (2016). The diverse voices conference: Expanding diversity education beyond the classroom. In C.L. Scott \& J.D. Sims (Eds.), Developing workforce diversity programs, curriculum and degrees in higher education (pp. 62-73). Hershey: PA: IGI Global.

Solorzano, D.G., \& Yosso, T.J. (2002). Critical race methodology: Counter-storytelling as an analytical framework for education research. Qualitative Inquiry, 8(1), 23-44. 